\title{
Oxidative toxic stress and p53 level in healthy subjects occupationally exposed to outdoor air Pollution - a cross-sectional study in Iran
}

\author{
Noushin Rezaei Vandchali ${ }^{1, A-D \oplus}$, Ali Koolivand ${ }^{2, A, C, E \oplus}{ }^{,}$, Akram Ranjbar ${ }^{3, C, E-F \oplus}$, Parvin Zarei ${ }^{1, B-C \oplus \odot}$, \\ Mojtaba Fathi ${ }^{4, B, D} \oplus$, Sheida Malekafzali ${ }^{5, B-C} \oplus$, Nargess Mollamohammadi ${ }^{1, B} \oplus$, \\ Farideh Jalali-Mashayekhi ${ }^{1, A, C-F}$ (i) \\ ${ }^{1}$ Department of Biochemistry and Genetics, Faculty of Medicine, Arak University of Medical Sciences, Arak, Iran \\ 2 Department of Environmental Health Engineering, Faculty of Health, Arak University of Medical Sciences, Arak, Iran \\ ${ }^{3}$ Department of Pharmacology and Toxicology, School of Pharmacy, Medicinal Plants and Natural Products Research \\ Center, Hamadan University of Medical Sciences, Hamadan, Iran \\ ${ }^{4}$ Department of Biochemistry, Faculty of Medicine, Zanjan University of Medical Sciences, Zanjan, Iran \\ ${ }^{5}$ The Policy Department of Health Governance Head of Secretariat of Supreme Council for Health and Food Security \\ Ministry of Health and Medical Education, Iran \\ A - Research concept and design, B - Collection and/or assembly of data, C - Data analysis and interpretation, \\ $D$ - Writing the article, $E$ - Critical revision of the article, $F$ - Final approval of article
}

Rezaei Vandchali N, Koolivand A, Ranjbar A, Zarei P, Fathi M, Malekafzali S, Mollamohammadi N, Jalali-Mashayekhi F. Oxidative toxic stress and p53 level in healthy subjects occupationally exposed to outdoor air Pollution - a cross-sectional study in Iran. Ann Agric Environ Med. 2020; 27(4): 585-590. doi: 10.26444/aaem/126313

\begin{abstract}
Introduction. It is suggested that air pollution exposure induces oxidative stress in the body and causes diseases. However, current evidence regarding the association of outdoor air pollution with some oxidative toxic stress (OTS) biomarkers in areas with different pollutant concentrations is equivocal.

Objective. The aim of study was to investigate the adverse effects of outdoor air pollution on human health, by evaluating potential oxidative and anti-oxidative biomarkers and p53 protein levels in subjects exposed to different outdoor air pollution from two polluted and less polluted cities of Iran.

Materials and method. In this cross-sectional study, a total of 203 healthy working men were selected from two cities. The activities of superoxide dismutase (SOD), catalase (CAT) and $\gamma$-glutamyltransferase (GGT) and the levels of malondialdehyde (MDA), total antioxidant capacity (TAC), and total oxidant status (TOS), were measured by the colorimetric method. The levels of p53 were measured by an ELISA method.

Results. The results showed a significant increase in the levels of p53 and MDA in the exposure group compared to the control group, while the activity of SOD and TAC was significantly decreased in the exposure group. No significant differences were found in activities of CAT and GGT, and levels of TOS between the two groups.

Conclusions. The findings obtained confirmed the implication of air pollution in the development of OTS, and suggested useful biomarkers to evaluate the air pollution-induced harmful effects on human health in the polluted areas.
\end{abstract}

\section{Key words}

air pollution, oxidative stress, human, p53 level, environment

\section{INTRODUCTION}

Air pollution is a challenging environmental and public health issue globally, especially in developing countries where the pollutant concentrations consistently exceed permissible levels [1]. Although there is considerable evidence regarding the adverse effects of air pollution on human beings, World Health Organization (WHO) experts believe that much remains to be fully elucidated [2]. The most important air pollutants include carbon monoxide (CO), ozone, sulfur dioxide $\left(\mathrm{SO}_{2}\right)$, nitrogen dioxide $\left(\mathrm{NO}_{2}\right)$, and most notably, particulate matter $\left(\mathrm{PM}_{2.5} \text { and } \mathrm{PM}_{10}\right)^{2}$ [3]. Epidemiological studies have shown a positive relationship between shortand long-term exposure to air pollution and mortality rates from different diseases [4]. Various studies have reported that

Address for correspondence: Farideh Jalali-Mashayekhi, Arak University of Medical Sciences, Iran

E-mail: mashayekhi@arakmu.ac.ir

Received: 01.05.2020; accepted: 10.08.2020; first published:04.09.2020 air pollution is one of the top ten major causes of death and leads to approximately 3 million deaths each year [5]. Acute or chronic exposure to air pollutants, as well as ionizing radiation and toxic chemicals, may produce reactive oxygen species (ROS), such as superoxide anion radical, hydrogen peroxide, and singlet oxygen, that induce oxidative toxic stress (OTS) in mammalian cells [6, 7]. OTS is characterized by the vifor cellular damage by lipid peroxidation (LPO), DNA damage, membrane protein devastation, antioxidant depletion, dysregulated gene expression, and apoptosis [8]. Therefore, air pollutants play an important role in the development of environmental associated diseases, such as cardiovascular diseases, respiratory diseases, cancer, neurotoxicity, liver damages, and systemic inflammation in humans, which are induced by excessive ROS [9]. Mammalian cells possess an antioxidant defence system that consists of the enzymes of superoxide dismutase (SOD), catalase (CAT), glutathione peroxidase (GPx), as well as some non-enzymatic antioxidants such as reduced glutathione 
(GSH) and vitamins $\mathrm{A}, \mathrm{C}$, and E. These antioxidants help the body to tackle the deleterious effect of ROS and diminish the cellular damage [10]. Importantly, SOD and CAT act as the first line of protection against ROS [11]. SOD catalyzes the breakdown of superoxide anion $\left(\mathrm{O}^{2-}\right.$ ) into the less potent oxidant hydrogen peroxide $\left(\mathrm{H}_{2} \mathrm{O}_{2}\right)$, and CAT acts by scavenging excessive $\mathrm{H}_{2} \mathrm{O}_{2}$, transforming it into water and molecular oxygen. Therefore, the combined action of these enzymes abates the production of superoxide radicals and hydrogen peroxide and consequently protects cellular components against ROS [12]. The homeostasis of GSH is preserved by $\gamma$-glutamyltransferase (GGT), which catabolizes extracellular GSH to produce amino acids and resynthesizes intracellular GSH. GGT enzyme and total thiol groups (TTG) are suggested as useful markers to study various environmental pollutant effects in the body [13]. Malondialdehyde (MDA) is an LPO marker and has been widely utilized to estimate cell damage induced by ROS [14]. OTS can also be evaluated by measuring total antioxidant capacity (TAC) and total oxidant status (TOS), which both reflect the oxidative and anti-oxidative status of the body [15].

Air pollution-induced oxidative stress can also target DNA, causing single- or double-strand breaks [16]. These events can lead to the activation of $\mathrm{p} 53$, which plays a critical role in regulating cellular response through cell cycle arrest or apoptosis. The $\mathrm{p} 53$ gene is a well-known tumour suppressor gene that codes for a $53 \mathrm{kD}$ nuclear phosphoprotein. This protein regulates apoptosis via upregulating Bax and downregulating $\mathrm{Bcl}_{2}$ or $\mathrm{Bcl}-\mathrm{xL}$. [17]. Few reports have used p53 as a biomarker for ailments or the detrimental health effects caused by environmental agents [18].

Recently, a great deal of effort has been devoted to investigating the relationship between human exposure to outdoor air pollution and oxidative stress, and the antioxidative defence status or ROS levels in the residents of polluted areas. A number of in vivo and in vitro studies have suggested some biomarkers to monitor the adverse health effects of some pollutants, such as $\mathrm{SO}_{2}, \mathrm{NO}_{2}$, PM, smoking, polycyclic aromatic hydrocarbon ( $\mathrm{PAH})$, formaldehyde and metals. Kamal, et al. used blood SOD activity and the urinary level of 8 - hydroxydeoxyguanosine (8-OHdG) to explore the status of oxidative stress and DNA damage in household women and professional male workers exposed to some environmental pollutants such as PAH [19]. Rumi Rabha showed that decreased levels of blood antioxidant, including SOD, CAT and GSH, as well as an elevated concentration of MDA, could be considered as potential biomarkers for oxidative stress in women exposed to fuelwood [20]. However, results of some studies are inconsistent and further investigations are needed to establish their potential biomarker significance. To the authors' knowledge, a few reports have used p53, TAC, TOS or GGT enzyme activity as potential biomarkers for the harmful effects caused by environmental agents such as air pollution.

\section{OBJECTIVE}

The aim of the study is to investigate the possible effects of outdoor air pollution on $\mathrm{p} 53$ protein level and oxidative and anti-oxidative parameters in the blood samples in subjects working in polluted areas of Iran (the city of Arak), compared with the control areas (the city of Zanjan).

\section{MATERIALS AND METHOD}

Study Area. This cross-sectional study was conducted in the cities of Arak and Zanjan. Arak, located in the centre of Iran, is among the most polluted cities in the country. The city of Zanjan is similar to Arak in terms of distributions of human population density and land area. According to a report by the Iranian Department of the Environment, the air quality in Zanjan is better than Arak; hence, this city was selected as a less polluted area for the study [21].

Study design and population of interest. The study population consisted of 203 healthy male employees of various organizations in the cities of Arak and Zanjan who attended in a health check programme from December 2015 - June 2016. Before the visit by the study team, a letter of invitation and study description was sent to all organizations. A response sheet was also provided to indicate their interest. All interested participants then had a health check-up in a health examination centre. Afterward, in-person interviews were carried out by student at the participants' work place. The participants completed questionnaires that provided information about individual characteristics, medical history, lifestyle, smoking history, and other general information regarding the work shift [work experience and average working time]. The subjects with a current or prior history of diabetes, cancer, liver diseases, kidney failure, lung disease, heart failure, and smoking were excluded from the study

Based on the above criteria, the exposed group consisted of 111 non-smoking subjects (males, aged 25-45 years) who were working in the downtown area of Arak and spent $>$ 8 h outdoors daily. The control group consisted of 92 nonsmoking volunteers (males, aged $25-45$ years) who spent $>8 \mathrm{~h}$ daily outdoors and working in the downtown area of Zanjan. All the participants had been living in Arak and Zanjan cities for more than three years. The specific jobs included in both groups were policemen, bus drivers, taxi drivers, and urban service workers. No differences in occupational, lifestyle and health status were found between volunteers in the study. All participants signed an informed consent form before being enrolled in the study. All participants also signed an informed consent form for blood sample collection and testing. The protocol for the study was approved by the Ethical Committee of Arak University of Medical Sciences (Ethics Code No. IR.ARAKMU.REC.1395.234).

Data collection. Air quality data was obtained from the archives of the Air Quality Monitoring stations in the cities of Arak and Zanjan. Air quality data is routinely collected from fixed air pollution monitoring stations located in the urban area of the cities. These stations routinely measure six pollutants, including $\mathrm{CO}, \mathrm{PM}_{2.5}, \mathrm{SO}_{2}, \mathrm{NO}_{2}, \mathrm{PM}_{10}$, and $\mathrm{O}_{3}$. The stations are not situated in the vicinity of industrial areas or major traffic regions, and are a sufficient distance from pollution sources.

Blood collection and measurement. Fasting blood samples of $5 \mathrm{ml}$ were drawn from the participants in the health examination centre. Blood specimens were subsequently centrifuged at 3,000 rpm for $10 \mathrm{~min}$ within $45 \mathrm{~min}$ of collection. Serums were aliquoted, coded, and stored at $-80^{\circ} \mathrm{C}$ for the determination of studied parameters. 
OTS biomarkers assay - Measurement of TAC and TOS. TAC of serum samples was measured by the ferric educing ability of plasma (FRAP) method, as previously described [22]. Briefly, this method is based on the capacity of serum antioxidants in reducing $\mathrm{Fe}^{3+}$ to $\mathrm{Fe}^{2+}$ in the acidic conditions and TPTZ. First, a mixture of FRAP reagent and serum was prepared and incubated at $37^{\circ} \mathrm{C}$. The absorption of the $\mathrm{Fe}^{2+}-$ TPTZ complex was then measured at $593 \mathrm{~nm}$, and correlated with the antioxidant capacity of serum samples.

TOS was measured as described by Ere [23]. The TOS assay is based on an oxidation reaction in the acidic medium. In this method, the oxidants in the sample oxidize $\mathrm{Fe}^{2+}$ to $\mathrm{Fe}^{3+}$. The ferric ion forms a coloured complex with xylenol as orange in an acidic medium. The absorbance of this coloured product was directly related to the concentration of oxidant in the sample. The measurements were obtained by using a spectrophotometer calibrated with hydrogen peroxide.

Measurement of MDA. MDA, as a byproduct of lipid peroxidation, was measured by a colorimetric method using thiobarbituric acid reactive substances (TBARS), as demonstrated previously [22]. Briefly, serum specimens were mixed with a solution containing TCA, TBA, and distilled water, and heated for $60 \mathrm{~min}$ in a boiling water bath. The mixture was then placed on cold water to reach room temperature. Subsequently, TBARS adducts were extracted by n-butanol, followed by centrifugation at $1,000 \mathrm{~g}$ for 10 mins. The layer, including $\mathrm{n}$-butanol, was removed and the absorbance of the solution measured at $532 \mathrm{~nm}$. The concentrations of MDA were estimated by using 1, 1, 3, 3 -tetraethoxy propane (TEP) as a standard.

Measurement of GGT activity. Serum GGT activity was determined using a commercially available kit (Pars Azmon Co, Iran) according to the manufacturer's instructions.

Measurement of SOD activity. Serum activity of the SOD enzyme was estimated using a SOD assay kit (Zellbio $\mathrm{GmbH}$, Catalog No. ZB-SOD-96A). Serum samples were analyzed according to the manufacturer's instructions. In this assay, one unit (U) of SOD activity is defined as the amount of enzyme that catalyzes the decomposition of $1 \mu \mathrm{mol}$ of $\mathrm{O}^{2-}$ to $\mathrm{H}_{2} \mathrm{O}_{2}$ and $\mathrm{O}_{2}$ in one minute.

Measurement of CAT activity. CAT activity was measured by a slight modification of the method described by Hadwan et al. [24]. Briefly, the activity of this enzyme was measured by incubating the sample with $65 \mathrm{mmol} / \mathrm{l} \mathrm{H}_{2} \mathrm{O}_{2}$, as substrate, in $60 \mathrm{mmol} / \mathrm{l}$ sodium-potassium phosphate buffer ( $\mathrm{pH} 7.4$ ) at $37^{\circ} \mathrm{C}$ for 3 minutes. The reaction was then stopped by the addition of ammonium molybdate. The absorbance of the yellow complex was measured at $374 \mathrm{~nm}$ against the blank.

Measurement of p53 level. The levels of p53 protein level in serum samples were measured using the p53 quantitative ELISA kit (Abcam's Human p53, Cat No. ab46067), which is a 'sandwich-type' immunoassay, according to the manufacturer's protocols. The coloured reaction product was then assayed with an ELISA reader (Stat Fax ${ }^{\circledR} 4200$, Microplate Reader, NEOGEN ${ }^{\circ}$ Corporation) at $450 \mathrm{~nm}$. The absorbance of this coloured product is directly proportional to the concentration of p53 in serum samples.
Statistical Analysis. The data were expressed as mean \pm SD and mean \pm SEM, as appropriate. The differences between the groups were analyzed using Mann-Whitney tests, using Graph Pad statistics software version 7. A value of $\mathrm{P}<0.05$ was considered as a statistically significant level.

\section{RESULTS}

Demographic characteristics of the subjects. The demographic characteristics of 203 subjects are included in Table 1. No significant differences were observed regarding age distribution between participants in the polluted and control areas $(36.0 \pm 6.4$ vs. $37.4 \pm 6.6$ years, respectively. $\mathrm{P}>0.05)$. The education level, work experience, average working time, position, and duration of residence did not show significant differences between groups.

Table 1. Demographic characteristics of the study populations

\begin{tabular}{|c|c|c|}
\hline Characteristics & $\begin{array}{l}\text { Control area } \\
\qquad(\mathrm{N}=92)\end{array}$ & $\begin{array}{l}\text { Polluted area } \\
\qquad(\mathrm{N}=111)\end{array}$ \\
\hline \multicolumn{3}{|l|}{ Age (years), n (\%) } \\
\hline $25-34$ & $63(68.5)$ & $75(67.6)$ \\
\hline $35-45$ & $29(31.5)$ & $36(32.4)$ \\
\hline \multicolumn{3}{|l|}{ Job, n (\%) } \\
\hline Policeman & $21(22.8)$ & $19(17.2)$ \\
\hline Bus driver & $26(28.3)$ & $34(30.6)$ \\
\hline Taxi driver & $25(27.2)$ & $30(27.0)$ \\
\hline Urban service worker & $20(27.7)$ & $28(25.2)$ \\
\hline \multicolumn{3}{|l|}{ Education, $\mathrm{n}(\%)$} \\
\hline Less than college & $57(62.0)$ & $70(63.1)$ \\
\hline College & $35(38.0)$ & $41(36.9)$ \\
\hline \multicolumn{3}{|c|}{ Work experience (years), n (\%) } \\
\hline $5-10$ & $71(77.2)$ & $82(73.9)$ \\
\hline$>10$ & $21(22.8)$ & $29(26.1)$ \\
\hline \multicolumn{3}{|c|}{ Average working time (h/day), n (\%) } \\
\hline $8-10$ & $84(91.3)$ & $105(94.6)$ \\
\hline$>10$ & $8(8.7)$ & $6(5.4)$ \\
\hline \multicolumn{3}{|l|}{ Position, n (\%) } \\
\hline Supervisor & $11(12.0)$ & $23(20.7)$ \\
\hline Subordinate & $81(88.0)$ & $88(79.3)$ \\
\hline \multicolumn{3}{|c|}{ Duration of residence (years), $\mathrm{n}(\%)$} \\
\hline $10-20$ & $5(5.4)$ & $9(8.1)$ \\
\hline$>20$ & $87(94.6)$ & $102(91.9)$ \\
\hline
\end{tabular}

*Data are reported as (n) (\%): total number found per group and in parenthesis the perceptual. Data are expressed as the mean \pm SD.

Outdoor Air pollution during sampling period. The annual average levels of $\mathrm{PM}_{10}, \mathrm{PM}_{2.5}, \mathrm{NO}_{\mathrm{x}}, \mathrm{SO}_{2}$, and $\mathrm{CO}$ in the polluted and control areas from December 2015 - June 2016 are described in Table 2. The residents of the polluted area were exposed to much higher levels of $\mathrm{PM}_{10}, \mathrm{PM}_{2.5}, \mathrm{NO}_{\mathrm{X}}$, $\mathrm{SO}_{2}$, and $\mathrm{CO}$ than those in the control area.

Table 2. Descriptive statistics of air pollution levels and meteorological variables in control area (Zanjan) and polluted area (Arak), Iran, 2015-2016

\begin{tabular}{lcc}
\hline Variables & $\begin{array}{c}\text { Control area } \\
\text { Mean } \pm \mathrm{SD}\end{array}$ & $\begin{array}{c}\text { Polluted area } \\
\text { Mean } \pm \mathrm{SD}\end{array}$ \\
\hline $\mathrm{PM}_{10^{\prime}}$ Annual 24h $\left(\mathrm{\mu g} / \mathrm{m}^{3}\right)$ & $51.43 \pm 34.24$ & $75.61 \pm 81.06$ \\
\hline $\mathrm{PM}_{2.5^{\prime}}$ Annual 24h $\left(\mu \mathrm{g} / \mathrm{m}^{3}\right)$ & $13.30 \pm 5.41$ & $23.45 \pm 25.14$ \\
\hline $\mathrm{NOx}^{\prime}$ Annual 24h $(\mathrm{ppb})$ & $77.9 \pm 39.41$ & $109.03 \pm 79.74$ \\
\hline $\mathrm{SO}_{2^{\prime}}$ Annual 24h $(\mathrm{ppb})$ & $12.80 \pm 8.79$ & $21.41 \pm 19.90$ \\
\hline $\mathrm{CO}$, Annual 24h $(\mathrm{ppm})$ & $2.80 \pm 1.80$ & $2.92 \pm 5.71$ \\
\hline
\end{tabular}

SD - Standard deviation; $\mathrm{PM}_{10}$ - Particulate meter with diameter $\leq 0 \mu \mathrm{m}_{;}, \mathrm{PM}_{25}-$ Particulate meter with diameter $\leq 2.5 \mu \mathrm{m} ; \mathrm{NOx}$ - Nitrogen oxides; $\mathrm{SO}_{2}$ - Sodium dioxide; $\mathrm{CO}$ - Carbon monoxide. 
Biochemical assays. All the data obtained, including the activities of SOD, CAT, and GGT enzymes and the levels of TAC, TOS, MDA and P53 in the serum specimens of each group, are summarized in Table 3 . As shown, the activity of SOD and the levels of TAC in the occupational group of the polluted area were significantly lower than that of the control group (Fig. 1, Fig. 4). In comparison to the control group, the levels of MDA and P53 in serum samples of subjects from the polluted area were significantly increased (Fig. 5, Fig. 7). No significant differences were observed in CAT and GGT activities and TOS level between the groups (Fig. 2, Fig. 3, Fig. 6).

Table 3. Comparison of SOD, CAT and GGT activities, TAC, MDA and p53 levels in serum of study participants from polluted and control areas

\begin{tabular}{|c|c|c|c|}
\hline Parameter & $\begin{array}{c}\text { Control area } \\
92\end{array}$ & $\begin{array}{c}\text { Polluted area } \\
111\end{array}$ & P-value \\
\hline \multicolumn{4}{|c|}{$\mathrm{SOD}[\mathrm{U} / \mathrm{L}] * 10^{3}$} \\
\hline $\bar{x} \pm$ SEM & $23.25 \pm 1.13$ & $19.60 \pm 0.69$ & \multirow{3}{*}{0.01} \\
\hline $\min .-\max$. & $9.43-61.53$ & $6.69-44.04$ & \\
\hline Median & 20.56 & 18.11 & \\
\hline \multicolumn{4}{|c|}{ CAT $[\mathrm{U} / \mathrm{L}]]^{*} 10^{3}$} \\
\hline $\bar{x} \pm$ SEM & $4.73 \pm 0.30$ & $4.67 \pm 0.21$ & \multirow{3}{*}{0.54} \\
\hline $\min .-\max$. & $0.89-18.48$ & $1.46-18.37$ & \\
\hline Median & 3.90 & 4.20 & \\
\hline \multicolumn{4}{|l|}{ GGT [U/L] } \\
\hline $\bar{x} \pm \mathrm{SEM}$ & $34.13 \pm 1.72$ & $33.92 \pm 1.62$ & \multirow{3}{*}{0.93} \\
\hline min.-max. & $11.30-98.00$ & $13.90-118.0$ & \\
\hline Median & 29.45 & 28.70 & \\
\hline \multicolumn{4}{|l|}{$\mathrm{TAC}[\mathrm{mol} / \mathrm{L}]$} \\
\hline $\bar{x} \pm$ SEM & $0.91 \pm 0.01$ & $0.87 \pm 0.01$ & \multirow{3}{*}{0.01} \\
\hline $\min .-\max$ & $0.67-1.02$ & $0.60-1.26$ & \\
\hline Median & 0.94 & 0.88 & \\
\hline \multicolumn{4}{|c|}{$\mathrm{MDA}[\mathrm{mol} / \mathrm{L}]^{*} 10^{-6}$} \\
\hline $\bar{x} \pm$ SEM & $1.28 \pm 0.03$ & $1.59 \pm 0.04$ & \multirow{3}{*}{$<0.0001$} \\
\hline $\min .-\max$. & $0.61-3.01$ & $0.80-2.95$ & \\
\hline Median & 1.24 & 1.50 & \\
\hline \multicolumn{4}{|c|}{$\operatorname{TOS}[\mathrm{mol} / \mathrm{L}] * 10^{-3}$} \\
\hline $\bar{x} \pm$ SEM & $0.02 \pm 0.0001$ & $0.02 \pm 0.0001$ & \multirow{3}{*}{0.14} \\
\hline min.-max. & $0.01-0.13$ & $0.01-0.05$ & \\
\hline Median & 0.02 & 0.02 & \\
\hline \multicolumn{4}{|c|}{$\mathrm{p} 53[\mathrm{U} / \mathrm{L}]]^{*} 10^{3}$} \\
\hline $\bar{x} \pm$ SEM & $1.50 \pm 0.10$ & $2.58 \pm 0.09$ & \multirow[t]{3}{*}{$<0.0001$} \\
\hline $\min .-\max$. & $0.50-7.30$ & $0.90-5.60$ & \\
\hline Median & 1.20 & 2.40 & \\
\hline
\end{tabular}

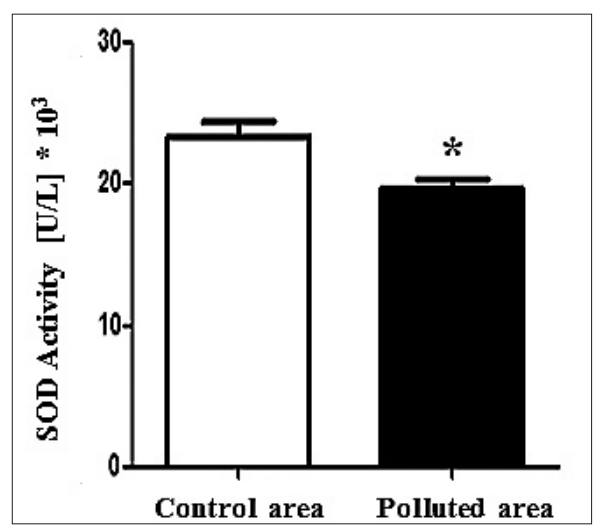

Figure 1. Level of serum SOD activity in control and exposed groups.

SOD - Superoxide dismutase activity. Data are presented as Mean \pm SEM. ${ }^{*} \mathrm{P}=0.01$

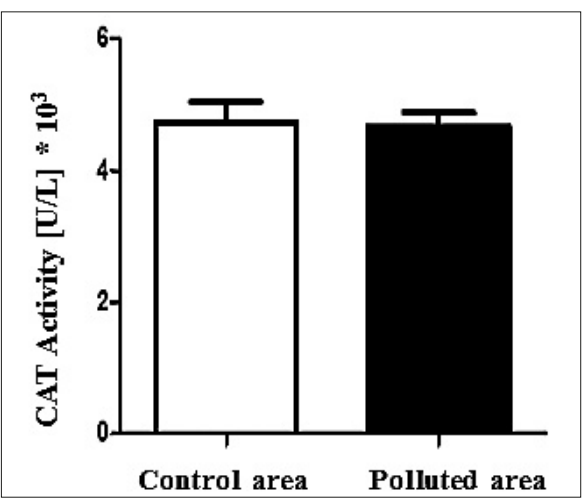

Figure 2. Level of serum CAT activity in control and exposed groups.

CAT - Catalase activity. Data are presented as Mean \pm SEM; $P=0.54$.

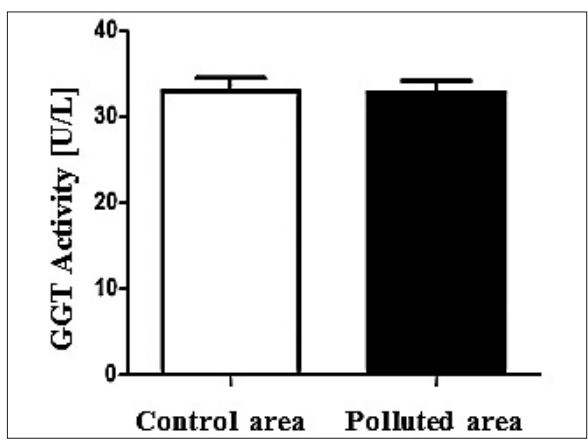

Figure 3. Level of serum GGT activity in control and exposed groups.

GGT - $\gamma$-glutamyltransferase. Data are presented as Mean $\pm \mathrm{SE} ; \mathrm{P}=0.93$.

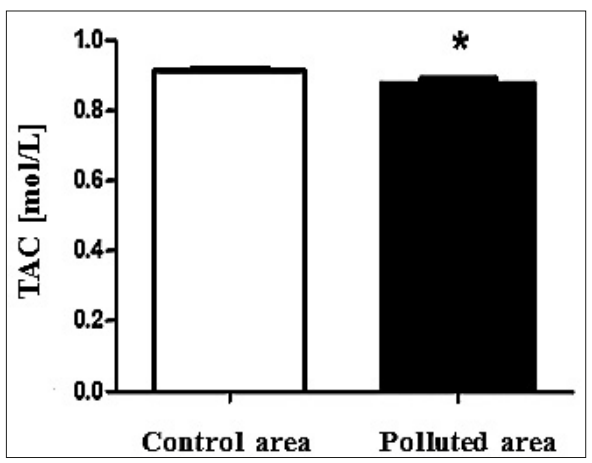

Figure 4. Comparison of the level of serum TAC in control and exposed groups.

TAC- Total antioxidant capacity. Data are presented as Mean \pm SEM. ${ }^{*} \mathrm{P}=0.01$.

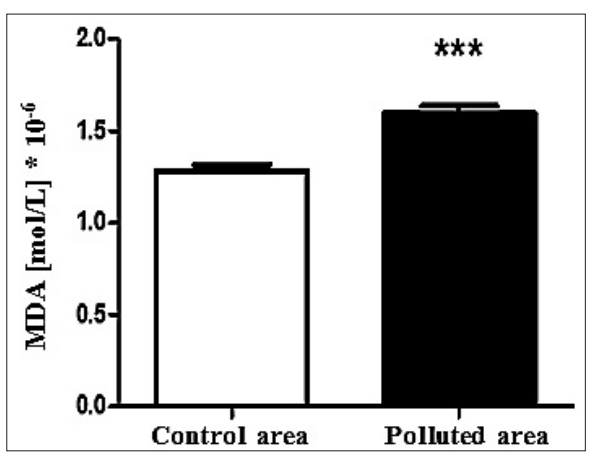

Figure 5. Level of serum MDA in control and exposed groups.

MDA - Malondialdehyde (MDA). Data are presented as Mean \pm SEM. ${ }^{* * *} \mathrm{P}<0.0001$. 


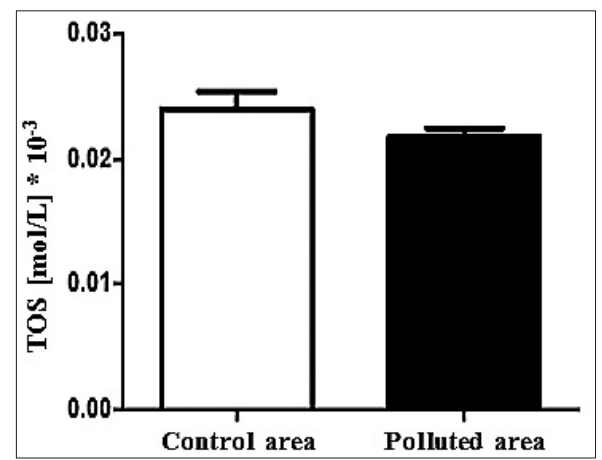

Figure 6. Level of serum TOS in control and exposed groups.

TOS - Total antioxidant status. Data are presented as Mean $\pm \mathrm{SEM} ; \mathrm{P}=0.14$

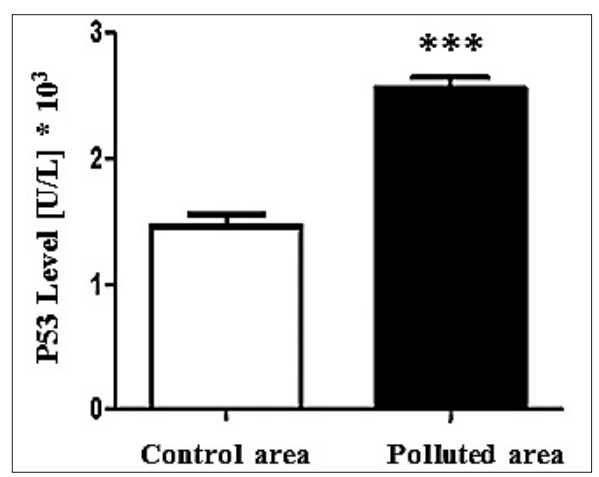

Figure 7. The level of serum p53 protein in control and exposed groups. Data are presented as Mean \pm SEM. ***P $<0.0001$

\section{DISCUSSION}

Exposure to air pollution has been repeatedly associated with numerous adverse health issues, and today is the matter of major concern. A range of different biomarkers is known to aid in assessing the effect of pollution exposure in vivo and in vitro [19]. In the current study, the activity of SOD, CAT, GGT enzymes and the levels of TOS, TAC, MDA, and p53 protein were investigated as response markers to outdoor air pollution in exposure groups consisting of policemen, bus drivers, taxi drivers, and urban service workers, in the cities of Arak and Zanjan in Iran. These jobs have been recognized as being important risk groups because of their constant exposure to outdoor air pollution. The results obtained (Tab. 2) show that the average levels of the pollutants in the polluted area were higher than those in the control area. According to the data obtained, the air pollution significantly decreased the activity of SOD in the serums of participants from the polluted area, compared to controls, but no remarkable differences were found in the activity of CAT and GGT between the two groups (Tab. 3).

To the authors' knowledge, few studies have investigated the relationship between exposure to outdoor air pollution and serum antioxidant enzyme activity, including SOD, CAT, and GGT $[25,26]$. On the other hand, some data support a role for pollutants in the development of oxidative stress and the alteration of the activity of antioxidant enzymes. The data of a recent investigation conducted by Hatice Gul Anlar, et al. showed that occupational silica exposure could alter the oxidative stress parameters, such as SOD and CAT in Turkish ceramic workers. They also found a significant reduction in the activities of SOD and CAT in all workers compared to control subjects [27]. Other experimental studies have shown that pollutant exposure to chromium or PAH can cause oxidative stress, as well as a significant increase in the enzyme activities of SOD and CAT [28, 29]. Residential exposure studies indicate that the doses and duration of exposure could cause both enhancement and decline in the activities of antioxidant enzymes [30]. SOD and CAT are the first-line antioxidants essential for aerobic organisms to decrease the levels of substances containing unpaired electrons, and thereby to prevent cellular damages caused by ROS [11]. The reduced activity of antioxidant enzymes such as SOD, may result in a decrease in their resistance to the deleterious impacts of the accumulation of superoxide anion and hydrogen peroxide [31]. Accordingly, the decreased activity of SOD in the current study may be due to the high levels of ROS induced by air pollution. However, no significant changes were found in the activity of CAT and GGT due to the exposure to outdoor air pollution. It was also observed that outdoor air pollution considerably augmented MDA and reduced TAC, but had no marked effect on TOS. It appears that the decreased TAC could not compensate the overwhelming effects of oxidative stress; hence, MDA as a biomarker of oxidative injury to the cell membrane was inevitably increased.

The current study revealed that p53 levels in the serums of the exposed subjects significantly increased in comparison to the control group. In agreement with the obtained results, a case-control study performed by Kiyonori Yamaoka et al. showed that the level of serum p53 in men in Misasa, Japan, was significantly higher than those in the control group [32]. In addition, a number of similar studies have reported that various air pollutants trigger apoptosis in all workers via the activation of $\mathrm{p} 53$ in their serum, plasma, and tissues $[18,33$, 34]. Since 553 is a well-known tumour suppressor gene, it was considered an unspecific biomarker of genotoxic stress [18]. Activation of $\mathrm{p} 53$, in response to DNA damage, is a significant mechanism that hampers tumour formation by genotoxic stress [35]. It is speculated that circulating $\mathrm{p} 53$ proteins can be increased in different ways. When the DNA damage is extensive, checkpoint activation can lead to p53 activation and apoptosis, which is generally induced by DNA-damage [36]. If environmental stress-induced DNA damage is unrepairable, the p53 protein supports DNA repair by stopping the cell cycle and promoting apoptosis [18]. The increased level of p53 indicates that the organism tries to rapidly mend cellular injury and protect itself from environmental stress, such as air pollution exposure [37]. Some investigations used other parameters including, plasma levels of $\mathrm{Gpx}, \mathrm{P} 21$, and urinary 8-OHdG, as a measurement of response to environmental pollutants in city policemen, bus drivers, and green space workers $[18,38-40]$. The inflammation factor has also been studied as a biomarker of traffic-related air pollution in taxi drivers [41]. However, evaluations of these biomarkers were not taken into consideration in the presented study due to the limited financial resources of this study. Certain limitations of this study are the wide range of pollutants and their production sources. Also, an incomplete generalization of the OTS biomarkers results is the contact with pollutants in such environments. Because these biomarkers indicate the damage caused by ROS in the human body, the damage may have underlying reasons other than air pollution. 
Further research with larger populations, additional markers, especially inflammatory cytokines, and more accurate measurement of environmental exposure are required to find a reliable and appropriate marker for assessing air pollution-induced OTS.

\section{CONCLUSIONS}

In the presented study a considerable difference was found in the activities of SOD and the levels of p53, MDA, and TAC in healthy exposed and control male employees of various organizations in the cities of Arak and Zanjan. The obtained results also indicate that no difference were observed in the activity of CAT, TOS and GGT, between the exposed and control groups. The study provides evidence proving the effect of outdoor air pollutants on some important serum OTS biomarkers, such as SOD, TAC, MDA and p53 protein. Some of these markers have been studied for the first time in the Iranian population occupationally exposed to air pollution. Therefore, the study suggests that these parameters can be used as biomarkers to monitor the influences of outdoor air pollution on the health of populations and individuals in the polluted areas. The study confirmed that increasing outdoor air pollution, as an important public health problem, needs to be addressed as a priority in the polluted areas of Iran.

\section{Acknowledgments}

This work has been extracted from the M.Sc. thesis of Noushin Rezaei Vandchali and was also funded by Grant Number 2661 from the Vice-chancellor for Research Affairs of Arak University of Medical Sciences. The authors would like to thank the volunteers who kindly participated in our research. We wish to acknowledge the support of the Iranian Department of Environment for the field work associated with this project.

\section{REFERENCES}

1. Kelly FJ, Fussell JC. Air pollution and public health: emerging hazards and improved understanding of risk. Environ Geochem Health 2015; 37(4): 631-649.

2. Henschel S, Chan G. Health risks of air pollution in Europe-HRAPIE project. Copenhagen, Denmark: World Health Organization, 2013.

3. Al-Baroud A, et al. Annual variations of air pollution in Jahra, Kuwait. GSTF J Engin Technol. (JET) 2017; 1(1).

4. Ancona C, et al. Mortality and morbidity in a population exposed to multiple sources of air pollution: A retrospective cohort study using air dispersion models. Environ Res. 2015; 137: 467-474.

5. Costa LG, et al. Neurotoxicants are in the air: convergence of human, animal, and in vitro studies on the effects of air pollution on the brain. BioMed Res Int. 2014. 2014

6. Zimet Z, et al. Lead Exposure and Oxidative Stress in Coal Miners. Biomed Environ Sci. 2017; 30(11): 841-845.

7. Salehi S, et al. Protective effects of resveratrol against X-ray irradiation by regulating antioxidant defense system. Radioprotection. 2018; 53(4): 293-298.

8. Renugadevi J, Prabu SM. Cadmium-induced hepatotoxicity in rats and the protective effect of naringenin. Exp Toxicol Pathol. 2010; 62(2): $171-181$

9. Ghorani-Azam A, Riahi-Zanjani B, Balali-Mood M. Effects of air pollution on human health and practical measures for prevention in Iran. J Res Med Sci. 2016; 21: 65

10. Pisoschi AM, Pop A. The role of antioxidants in the chemistry of oxidative stress: A review. Eur J Med Chem. 2015; 97: 55-74.

11. Ighodaro $\mathrm{O}$, Akinloye O. First line defence antioxidants-superoxide dismutase (SOD), catalase (CAT) and glutathione peroxidase (GPX): Their fundamental role in the entire antioxidant defence grid. Alex J Med. 2018; 54(4): 287-293.

12. Ito Y, et al. Mortality rates from cancer or all causes and SOD activity level and $\mathrm{Zn} / \mathrm{Cu}$ ratio in peripheral blood: population-based follow-up study. J Epidemiol. 2002; 12(1): 14-21.
13. Lee DH, Jacobs DR. Is serum gamma-glutamyltransferase a marker of exposure to various environmental pollutants? Free Radic Res. 2009; 43(6): p. 533-7.

14. Tsikas D. Assessment of lipid peroxidation by measuring malondialdehyde (MDA) and relatives in biological samples: Analytical and biological challenges. Anal Biochem. 2017; 524: 13-30.

15. Motor S, et al. Evaluation of total antioxidant status, total oxidant status and oxidative stress index in patients with alopecia areata. Int J Clin Exp Med. 2014; 7(4): 1089-93.

16. Minakawa Y, et al. Gamma-irradiated quiescent cells repair directly induced double-strand breaks but accumulate persistent double-strand breaks during subsequent DNA replication. Genes to Cells 2016;21(7): 789-797.

17. De Zio D, Cianfanelli V, Cecconi F. New insights into the link between DNA damage and apoptosis. Antioxid Redox Signal. 2013; 19(6): 559-71.

18. Rossner P, et al. Air pollution by carcinogenic PAHs and plasma levels of p53 and p21 WAF1 proteins. Mutation Res/Fundam Mol Mech Mutagen. 2007; 620(1): 34-40.

19. Kamal A, et al. Biomarkers of PAH exposure and hematologic effects in subjects exposed to combustion emission during residential (and professional) cooking practices in Pakistan. Environ Sci Pollut Res Int. 2016; 23(2): 1284-99.

20. Rabha R, Ghosh S, Padhy PK. Indoor air pollution in rural north-east India: Elemental compositions, changes in haematological indices, oxidative stress and health risks. Ecotoxicol Environ Saf. 2018; 165: 393-403.

21. Ghadimi F. Assessment of heavy metals contamination in urban topsoil from Arak industrial City, Iran. J Tethys. 2014; 2(3): 96-209.

22. Ranjbar A, et al. Oxidative stress in acute human poisoning with organophosphorus insecticides; a case control study. Environ Toxicol Pharmacol. 2005; 20(1): 88-91.

23. Erel O. A new automated colorimetric method for measuring total oxidant status. Clin Biochem. 2005; 38(12): 1103-11.

24. Hadwan MH. Simple spectrophotometric assay for measuring catalase activity in biological tissues. BMC Biochem. 2018; 19(1): 7.

25. Farhat Z, et al. How do glutathione antioxidant enzymes and total antioxidant status respond to air pollution exposure? Environ Int. 2018; 112: 287-293.

26. Wu S, et al. Ambient particulate air pollution and circulating antioxidant enzymes: A repeated-measure study in healthy adults in Beijing, China. Environ Pollut. 2016; 208(Pt A): 16-24.

27. Anlar HG, et al. Effects of occupational silica exposure on oxidative stress and immune system parameters in ceramic workers in Turkey. J Toxicol Environ Health. 2017; 80(13-15): 688-696.

28. Ateeq M, et al. Occupational risk assessment of oxidative stress and DNA damage in tannery workers exposed to Chromium in Pakistan. 2016.

29. Kamal A, et al. PAH exposure and oxidative stress indicators of human cohorts exposed to traffic pollution in Lahore city (Pakistan). Chemosphere, 2015; 120: 59-67.

30. Patra R, Swarup D, Dwivedi S. Antioxidant defence and lipiod peroxide level in liver and kidneys of lead exposed rat. 2018.

31. Van Raamsdonk JM, Hekimi S. Deletion of the mitochondrial superoxide dismutase sod-2 extends lifespan in Caenorhabditis elegans. PLoS genetics. 2009; 5(2): e1000361.

32. Yamaoka $\mathrm{K}$, et al. The elevation of $\mathrm{p} 53$ protein level and SOD activity in the resident blood of the Misasa radon hot spring district. J Radiat Res. 2005; 46(1): 21-24.

33. Attia D, et al. Assessment of lipid peroxidation and $\mathrm{p} 53$ as a biomarker of carcinogenesis among workers exposed to formaldehyde in the cosmetic industry. Toxicol Ind Health. 2016; 32(6): 1097-1105.

34. Hanaoka T, et al. Elevated serum levels of pantropic p53 proteins in chromium workers. Scan J Work Environ Health. 1997: 37-40.

35. Soberanes S, et al. p53 mediates particulate matter-induced alveolar epithelial cell mitochondria-regulated apoptosis. Am J Respir Crit Care Med. 2006; 174(11): 1229-1238.

36. Wang W, et al. PM2. 5 induced apoptosis in endothelial cell through the activation of the p53-bax-caspase pathway. Chemosphere, 2017; 177: 135-143.

37. Zhao H, et al. PM2. 5-induced alterations of cell cycle associated gene expression in lung cancer cells and rat lung tissues. Environ Toxicol Pharmacol. 2017; 52: 77-82.

38. Farhat Z, et al. How do glutathione antioxidant enzymes and total antioxidant status respond to air pollution exposure? Environ Int. 2018; 112: 287-293.

39. Mehrdad R, Aghdaei S, Pouryaghoub G. Urinary 8-hydroxydeoxyguanosine as a biomarker of oxidative DNA damage in employees of subway system. Acta Med Iranica. 2015; 53(5): 287-292.

40. Guilbert A, et al. Personal exposure to traffic-related air pollutants and relationships with respiratory symptoms and oxidative stress: A pilot cross-sectional study among urban green space workers. Sci Total Environ. 2019; 649: 620-628.

41. Barth A, et al. Association between inflammation processes, DNA damage, and exposure to environmental pollutants. Environ Sci Pollution Res. 2017; 24(1): 353-362. 